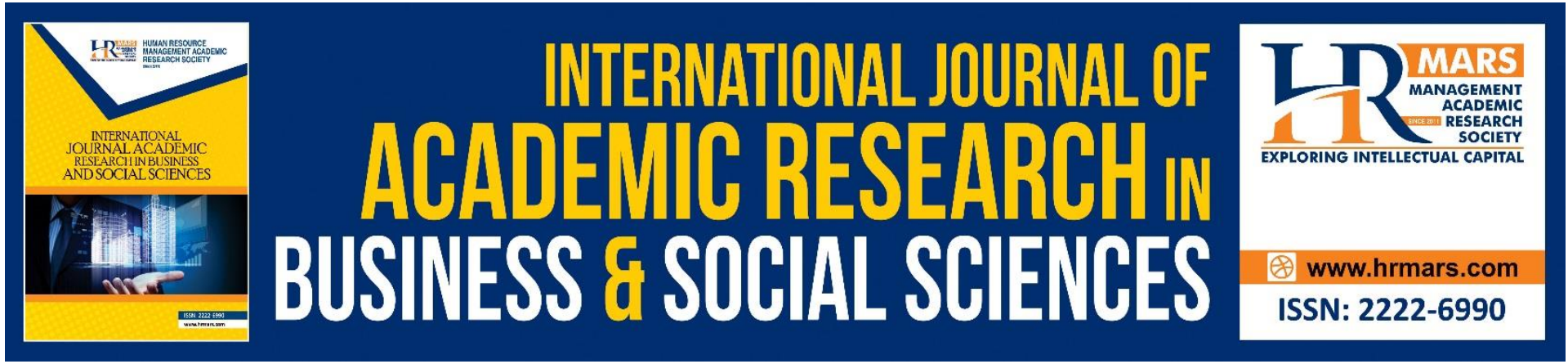

\title{
Identification of Business Intelligence in Managing Maintenance Management for Government Office Buildings in Putrajaya
}

Ain Farhana Jamaludin and Muhammad Najib Razali

To Link this Article: http://dx.doi.org/10.6007/IJARBSS/v11-i6/10216

DOI:10.6007/IJARBSS/v11-i6/10216

Received: 09 April 2021, Revised: 18 May 2021, Accepted: 30 May 2021

Published Online: 17 June 2021

In-Text Citation: (Jamaludin \& Razali, 2021)

To Cite this Article: Jamaludin, A. F., \& Razali, M. N. (2021). Identification of Business Intelligence in Managing Maintenance Management for Government Office Buildings in Putrajaya. International Journal of Academic Research in Business and Social Sciences, 11(6), 856-864.

Copyright: @ 2021 The Author(s)

Published by Human Resource Management Academic Research Society (www.hrmars.com)

This article is published under the Creative Commons Attribution (CC BY 4.0) license. Anyone may reproduce, distribute, translate and create derivative works of this article (for both commercial and non-commercial purposes), subject to full attribution to the original publication and authors. The full terms of this license may be seen at: http://creativecommons.org/licences/by/4.0/legalcode

Vol. 11, No. 6, 2021, Pg. 856- 864

Full Terms \& Conditions of access and use can be found at http://hrmars.com/index.php/pages/detail/publication-ethics 


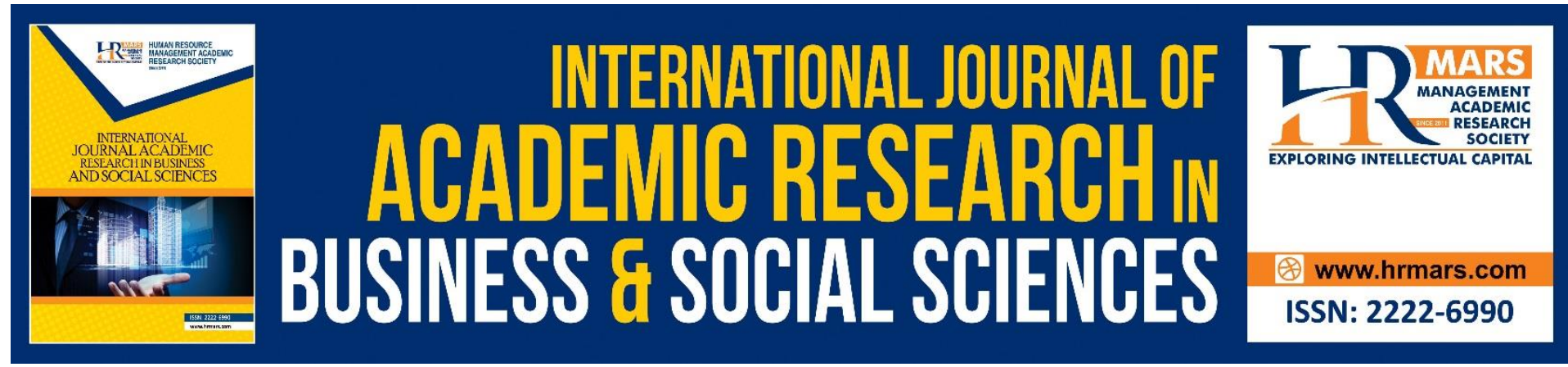

\title{
Identification of Business Intelligence in Managing Maintenance Management for Government Office Buildings in Putrajaya
}

\author{
Ain Farhana Jamaludin and Muhammad Najib Razali \\ Department of Real Estate, University Technology Malaysia Johor Bahru, 81310 Malaysia
}

\begin{abstract}
A proper data management in maintenance practices are required to make the daily process smooth. With the ability of Information Technology (IT) will influence on maintenance management database system. However, this IT systems are challenged with massive increases in amount of data, the speed they are generated and the need to record, process and visualize those data in real time to the user. This rapid growth of information results in the pervasion of Big Data (BD) and Business Intelligence (BI). This research highlights Public Works Department or Jabatan Kerja Raya (JKR) as a key pillar in managing and store important data relating to maintenance management for each building in Putrajaya. JKR finds difficulties to create sustainable maintenance policy which require the right tools and equipment to achieve sustainable goals and objective. Last research attentions have been given to the use of big data and business intelligence in maintenance management industries particularly in government sector. Hence, this research presents an analysis of the complexities and requirement for maintenance that focuses on intelligent system that help to improve the intelligent management of maintenance in making informed decision and can be applied horizontally to address identified challenges in practices.
\end{abstract}

Keywords: Data Management, Big Data, Business Intelligence, Maintenance

\section{Introduction}

In recent years, the flood of data with high speed and many variations has challenged the limited storage and conventional data mining methods. Traditional processing software incapable to handle the large amount of unstructured data whereby this massive amount of data generation is called as Big Data (BD) (Walker, 2014). While, on the part of government, in this context Public Work Department or very knows as Jabatan Kerja Raya (JKR) is a key pillar in managing ministry buildings in Putrajaya and definitely store important data relating to maintenance management for each building. To achieve the highest level of Information Technology (IT) in government especially maintenance management, the public sector has established CMMS (Computerized Maintenance Management System), SPFB (Sistem Pengurusan Fasiliti Berpusat) or known as Centralized Facility Management System and MySpata application to monitor daily maintenance management work by contractor and act as a database for strengthen government asset management and storage. The system created to closely monitor and control workflow of maintenance activities if necessary. And the 
amount of data accumulated and information provided out of data processing is highly misbalanced. Often, the government has no idea how to optimize and harness this data and use it for good. Thus, probability of making a quality maintenance management decision decrease.

In this era, a world of Internet of Things (IOT) approaches has been developed to analyze and handled the massive volume of data generated such as big data and business intelligence. Consequently, our government in this context needs faster insight towards the growing volume of data transaction. Analyzing data in real time helps government to foresee the past and future maintenance things by knowing what occurred (descriptive), why it happened (diagnostic), what will happened (predictive) and how to influence future action (prescriptive) (Ajah \& Nweke, 2019) shown in Figure 2.

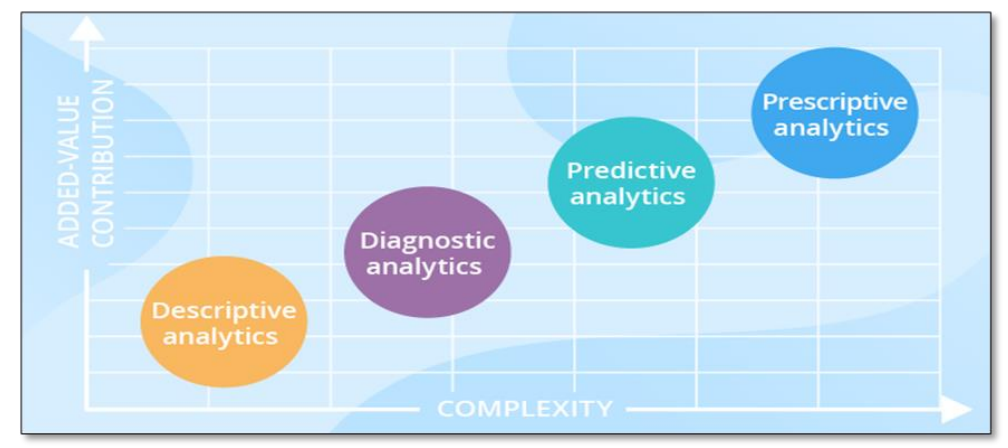

Figure 1. Big Data Analytics Complexity

A range of issues have been identified with related to data management challenge in government context which are; data acquisition; rapid flow of information; data quality; voluminous and heterogeneous data; data scarcity and data integration (Aljumaili et al., 2015). Previous research claimed that not enough technology integration in local government activities (Haneem et al., 2019). The adoption of big data and business intelligence in managing data management for government particularly on maintenance part has remain slow. This is evidenced whereby the system created unable to provide a real time and single database to ease the decision making. The current stake of the data is semi automation where data is scattered everywhere among vendors which have been appointed by the JKR (Jones et al., 2008).

In addition, it is important to provide a large-scale data repository to support data access for multiple users government since the information from different ministries buildings are not seamless (Desouza \& Jacob, 2017). Based on the literature review, most of the big data and business intelligence adoption studies have been conducted by various researchers and industries over a decade due to its vital applications of big data in various area such as healthcare system, educational development, network, travel estimation and financial services (He et al., 2016; Lieberman, 2014; Wang et al., 2015). These areas are generating a huge amount of data that require big data analytics process for effective and efficient decision making (Ajah \& Nweke, 2019). To the best of the knowledge of the researcher, least research attentions has been given to the use of big data and business intelligence in maintenance management industries particularly in government sector. Various research studies Big Data in certain area such; Wu et al., (2014) review hardware and software parameters for effective big data analytics development. Athanasopoulos et al., (2011), presented big data forecasting 
in tourism sector, their advantages and drawbacks. Conversely, our study differs with their review in many ways. To address the problem with data management in maintenance by Malaysian local government, this study examines the influence of big data and business intelligence integration in managing data management for maintenance particularly JKR in Putrajaya. This research aims to develop maintenance management simulation model by using Microsoft Power BI (Business Intelligence) with large repository database system in guiding JKR on making informed decision based on data.

\section{Literature Review}

\section{Big Data (BD) and Business Intelligence (BI)}

$B D$ has now become a new field that requires information and integration of information systems. The evolution of BD has attracted both academic and professional experts. In the business industry in Malaysia, it has also shown the need for the use of BD in business decision-making and improving efficiency. Conventionally, BD is often referred to as the Vs: Volume of data, Velocity of data and Variety of data (Desouza \& Jacob, 2017; Laney, 2001). The definition from (Haneem et al., 2019) stated that BD is not limited to data size, as datasets will increase in the future. It emphasizes the need for technology to overcome the rapid growth of existing dataome organisations see BD as a helpful tool in forming strategies and making decisions, whilst academic scholars use it as a basis for validating existing models and theories. It is noted that BD is a large volume of data, has high speed, includes various types of information needed, is cost effective and has innovative information processing to enhance decision-making (Su \& Chiong, 2010).

While, $\mathrm{BI}$ can be defined as a system that serves as a combination of operational data gathering, storage of data, knowledge management with analytical tools to present information to decision makers or planners. It has been explained as having "the right access to the right data or information needed to make the right business decisions at the right time according to Dayal et al., (2009). BI has also been defined as a process involving the converting of data into information and then into knowledge. It's been characterized as business management term which refers to applications and technologies which are used to gather, provide access to, and analyze data and information about company operations. It's been characterized as business management term which refers to applications and technologies which are used to gather, provide access to, and analyze data and information about company operations. According to (Su \& Chiong, 2010), BI tools help to intelligently and automatically transform the processed data into insights and knowledge. Through $\mathrm{Bl}$, visual reports, trendreviewing and key-performance indicators are able to be created (Dayal et al., 2009). BI works better with massive amount of data (BD) to provide accurate and complete maintenance data in order to create maintenance dashboard database system. Through BD, BI able to deliver insights, identify issues and informed decision can be made in real time. Within BI lies data management, which includes a broad spectrum of applications used throughout the entire $\mathrm{BI}$ system. The advent of computing and internet technologies have facilitated collection of a large volume of heterogeneous data from multiple sources on an ongoing basis posing new challenges and opportunities for business intelligence. Intelligent maintenance system able to predict and forecast equipment perfomance such as mechanical, civil and electrical so "zero-breakdown" status is possible. 


\section{Data Management of Maintenance Management}

The maintenance management industry, to some degree is experiencing the same trend as other industries regarding its data generation, storage and management. To add, the industry of maintenance management is experiencing e-maintenance which is an emerging concept whereby assets are monitored and managed over the Internet (Horan, 2010). This concept creates a platform for sharing data all over the enterprise, increases the process efficiency and results in more cost-effective decisions. It's easier to acquire data from different sources, process larger data sizes and increase data usability to assure information quality for a more productive maintenance system. Maintenance management as a type of business process is highly dependent on large amounts of data from which relevant information can be created and is used for decision-making during the life-cycle of assets. In deciding the maintenance decision of a building, the maintenance manager should have complete information on maintenance data. This is why data management is necessary for JKR in managing maintenance as the data will affect on maintenance decision made by top management (Horan, 2010). Data management challenge has been studied with narrow focus to data especially in government side and appear as one of the less studied topics in the literature. The reason for this is probably because the problems with data management adoption are only being realized ten years after its establishment (Kumar et al., 2017). A study in 2012 highlighted that poor document processes were a primary agent leading to risk, with process owners reporting defective document-driven business processes exposing companies to serious business risks and/or compliance issues (Horan, 2010).

\section{Methods: Microsoft Power Business Intelligence (PBI) Analytics for Maintenance Management Data}

This chapter dedicate to explain on the process of Microsoft Power Business Intelligence (Microsoft Power $\mathrm{BI}$ ) able to use big data concept for maintenance management for government building in Putrajaya. As previously mentioned, the current stake of the data is semi automation where data is scattered everywhere among vendors and with the increasing availability of data especially on maintenance management it has become more challenges and opportunities for government to champion of the modernisation of the data management in systematic way. Microsoft Power BI as one of business intelligence tools has recently added data management features that help achieve this symbiosis (Dutta, 2019). This research has employed Microsoft Power $\mathrm{BI}$ (Microsoft PBI) which able to bring advanced analytics to manage data management of maintenance operation of government buildings in Putrajaya. Microsoft PBI will put advanced analytics to the maintenance operation decision process, systematic data management, statistical analysis and maintenance problems. The Microsoft Power BI platform ensures good data curation, origin and protection, and reduces distractions through simple, non-intrusive governance features. The way Power BI works is different from the ways that the industry has traditionally used. The traditional way means that consumers have to use more than one platform to include data management in their $\mathrm{BI}$ flows. While, using this a dashboard of maintenance management can be create at a glance. This research focused on major maintenance data; mechancal, civil, electrical, housekeeping, landscape and pest control. According to (Gao \& Lee, 2017), the BI system should have a following basic features: Data Management, Data Analysis and Knowledge Discovery. 


\section{Microsoft Power BI Features}

\section{a) Quick Insights Feature}

First feature in Microsoft Power $\mathrm{BI}$ which is built on a growing set of advanced analytical algorithms which is developed in conjunction with Microsoft Research. This feature will allow users to find insight in the data in new and intuitive ways. With a simple click, users able to use Quick Insight in power BI searchers different subsets of the data while applying a set of sophisticated algorithms to discover potentially interesting insights.

\section{b) Segmentation and Cohort}

It is a simple but powerful way to explore data and identify deviations from the norm. This features able users to simply the act of breaking down or combing data into meaningful groups, and then comparing those groups to identify meaningful relationships in the data. It is typically used to develop a hypothesis on the data and identify areas for further analysis. Power BI able to clustering, grouping and binning.

\section{c) Data Clustering}

Power $\mathrm{BI}$ will customise the visuals for further analysis and evaluation of the clusters. For instance, this feature able to cluster column and each of the associate measures in a radar chart to see the aggregate of each measure for each cluster. Users able to the cluster column and one of the measures in a box and whiskers plot to see the distribution of values for that measure in each cluster. This will able users to assess the minimum, maximum and median values for the measure within each cluster.

\section{d) Data Streaming}

Power BI will also able to let the data display and analyse in real time data which empower the organisation to gain instant insights from time-sensitive information. Predictive intelligence able to take proactive action to stay on the right course and stream analytics which able to shape and aggregate the data.

Although in the current practice of maintenance data management is semi automation which inspection data just has been recorded by using papers and files then all the data transferred to Microsoft Excel, the best practice which can be done is to rearrange the current data in Excel to follow the big data concept in business intelligence based on the previous explanation. Figure 2 shows the mechanical assets of buildings data that has been rearrange according to the big data concept. In order for these data could be transferred to Power $\mathrm{BI}$, it needs to be reformatted into Power BI "Table" format. Therefore, column 1 to Column 11 are important element for the purpose of Power BI system.

\begin{tabular}{|c|c|c|c|c|c|c|c|c|c|c|}
\hline COLUMV1 & COLUMN2 & COLUMN3 & COLUMN4 4 & COLUMN5 & COLUMING & COLUMN7 & COLUMN8 & COLUMNG & COLUMN10 & COLUMN11 \\
\hline No. & Aset & Kod Blok & Kod Aras & Kod & Kod Aset & $\begin{array}{c}\text { Installation } \\
\text { Year }\end{array}$ & Service Period & $\begin{array}{l}\text { Upgrading } \\
\text { Year }\end{array}$ & Warranty & Remark \\
\hline 1 & AIRCOOLED SPLIT UNIT & D1 & ACSU-D1-B1-SDF-1 & 100000 & Mekanikal & Mei-99 & 18 Years & Ogos-14 & - & - \\
\hline 2 & & D1 & ACSU-D1-B1-SDF-2 & 100001 & \begin{tabular}{|l|} 
Mekanikal \\
\end{tabular} & Mei-99 & 18 Years & Ogos-14 & - & $\cdot$ \\
\hline 3 & & D1 & ACSU-D1-B1-SDF-3 & 100002 & Mekanikal & Mei-99 & 18 Years & Ogos -14 & $\cdot$ & $\cdot$ \\
\hline 4 & & D1 & ACSU-D1-B1-SDF-4 & ACSU-D1-B1-4 & \begin{tabular}{|l|} 
Mekanikal \\
\end{tabular} & Mei-99 & 18 Years & na & - & upgrade required \\
\hline 5 & & D1 & ACSU-D1-B1-PABX-1 & 100003 & Mekanikal & Mei-99 & 18 Years & Ogos -14 & - & $\cdot$ \\
\hline 6 & & D1 & ACSU-D1-B1-PABX-2 & 100004 & Mekanikal & Mei-99 & 18 Years & Ogos-14 & $\cdot$ & $\cdot$ \\
\hline 7 & & D1 & ACSU-D1-B1-UPS-1 & ACSU-D1-B1-1 & Mekanikal & Mei-99 & 18 Years & na & - & upgrade required \\
\hline 8 & & D1 & ACSU-D1-B1-UPS-2 & ACSU-D1-B1-2 & Mekanikal & Mei-99 & 18 Years & nia & - & upgrade required \\
\hline 9 & & D1 & ACSU-D1-RF-LMR-1 & 100005 & \begin{tabular}{|l|} 
Mekanikal \\
\end{tabular} & Mei-99 & 18 Years & Ogos-14 & - & $\cdot$ \\
\hline 10 & & D1 & ACSU-D1-RF-LMR-2 & 100006 & Mekanikal & Mei-99 & 18 Years & Ogos -14 & - & - \\
\hline 11 & & D1 & ACSU-D1-AF-LMR-3 & 100007 & Mekanikal & Mei-99 & 18 Years & Ogos-14 & - & $\cdot$ \\
\hline
\end{tabular}

Figure 2 Maintenance Management Data - Mechanical (Excel Format) 
Next process the data were deployed and configure in a local storage in case of data stalled communication and Microsoft Azure loT hub to handle the data ingestion. This need administrator to write a node's service to store data on the device in the mechanical assets with the purpose of preserving messages and storing those that have not yet been sent to cloud. One of the important tools in Power BI is SQL Database which provides high-end security features that able to configure in order to ensure data security. This is known as 'Data Rest' which to predict failure in assets or tools. By using machine learning, the device can be trained to predict a failure by analysing past data. After transferring the excel format through Microsoft Power $\mathrm{Bl}$, the output is shown as Figure 3. The simulation model of maintenance dashboard able to provide all information regarding on maintenance and equipment that related to buildings at the grass-roots with access to wide ranging data sources in a simple to use, consolidated way to improve decisions about assets, risk and operations. In Power $\mathrm{BI}$, all data can view under one repository database system and users also able to view in 'focus mode' which means to view each of the graph in details and interactive.

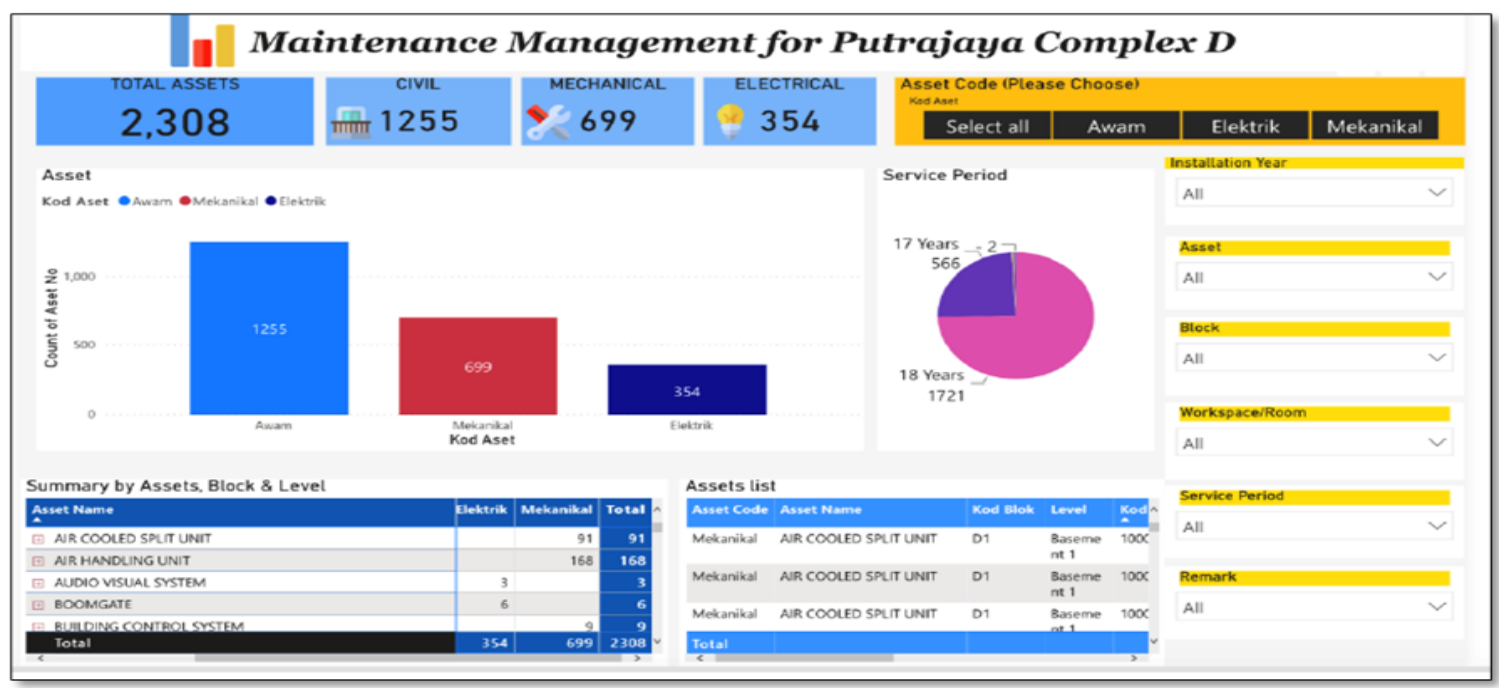

Figure 3 Maintenance Management Simulation Model in Government Office Buildings of Putrajaya in Complex D

Findings: Enabling New Kind of Data Repository System in Maintenance Management

$\mathrm{BD}$ and $\mathrm{BI}$ through Microsoft Power BI brings visualisation of the data insight to users in the Dashboard which create by the system developer or administrator also support with other devices which able to create real-time monitoring. Furthermore, it will schedule the maintenance operations and thereby reduced the cost. The most important thing to put Power BI to manage data in maintenance management is that the entire loT architecture and set up is maintained independent of the existing mechanical system, hence it will not interfere with the working of the mechanical system or its maintenance at any point and also it will be very reliable under all circumstances. In Power $\mathrm{BI}$, all data can view under one dashboard and users also able to view in 'focus mode' which means to view each of the graph in details and interactive.

\section{Conclusions}

Author believes with $\mathrm{BD}$ and $\mathrm{BI}$ integration in maintenance management particularly in government sector will improve the database management system and required the user to become more literate and has a skill to understand data and analytical concepts that currently seems out of reach including statistical methods, machine learning and data manipulation. In 
the emerging of data literacy which become more powerful ability to make organisation more advance in term of decision making which mostly rely on the smart use of data rather than based on gut feeling and top management decision. This research has employed Microsoft Power $\mathrm{BI}$ (Microsoft PBI) which able to bring advanced analytics to manage maintenance operation and able to reduce cost or identify assets sustainability in reducing energy consumption in government buildings of Putrajaya. With the tools in the big data in business intelligence model, all level of maintenance management which in certain circumstances need urgent decision able to dive into their own analytics and uncover powerful insights

\section{Acknowledgement}

We would like to acknowledge Ministry of Higher Education Malaysia for funding through Fundamental Research Grant Scheme (FRGS) Vot 5F257. In addition, we would like to acknowledge UTM for management of this grant.

\section{Corresponding Author}

Ain Farhana Jamaludin, Department of Real Estate, Faculty of Built Environment, University Technology Malaysia, Johor Bahru, Malaysia

Email: a.farhana19@yahoo.com

\section{References}

Ajah, I. A., \& Nweke, H. F. (2019). Big data and business analytics: Trends, platforms, success factors and applications. Big Data and Cognitive Computing, 3(2), 1-30. https://doi.org/10.3390/bdcc3020032

Aljumaili, M., Wandt, K., Karim, R., \& Tretten, P. (2015). EMaintenance ontologies for data quality support. Journal of Quality in Maintenance Engineering, 21(3), 358-374. https://doi.org/10.1108/JQME-09-2014-0048

Athanasopoulos, G., Hyndman, R. J., Song, H., \& Wu, D. C. (2011). The tourism forecasting competition. International Journal of Forecasting, 27(3), 822-844. https://doi.org/10.1016/j.ijforecast.2010.04.009

Dayal, U., Kuno, H., Wiener, J. L., Wilkinson, K., Ganapathi, A., \& Krompass, S. (2009). Managing operational business intelligence workloads. Operating Systems Review (ACM), 43(1), 92-98. https://doi.org/10.1145/1496909.1496927

Desouza, K. C., \& Jacob, B. (2017). Big Data in the Public Sector: Lessons for Practitioners and Scholars. Administration and Society, 49(7), 1043-1064. https://doi.org/10.1177/0095399714555751

Dutta, P. (2019). Business Analytics using Microsoft Power BI and AWS Redshift. International Journal of Trend in Scientific Research and Development, Volume-3(Issue-2), 984-986. https://doi.org/10.31142/ijtsrd21545

Haneem, F., Kama, N., Taskin, N., Pauleen, D., \& Abu Bakar, N. A. (2019). Determinants of master data management adoption by local government organizations: An empirical study. International Journal of Information Management, 45(April 2018), 25-43. https://doi.org/10.1016/j.ijinfomgt.2018.10.007

He, Y., Yu, F. R., Zhao, N., Yin, H., Yao, H., \& Qiu, R. C. (2016). Big Data Analytics in Mobile Cellular Networks. IEEE Access, 4, 1985-1996.

https://doi.org/10.1109/ACCESS.2016.2540520

Walker, J. S. (2014). Big Data: A Revolution That Will Transform How We Live, Work, and Think. International Journal of Advertising, 33(1). https://doi.org/10.2501/ija-33-1-181-183 
Jones, S., Ball, A., \& Ekmekcioglu, Ç. (2008). The Data Audit Framework: A First Step in the Data Management Challenge. International Journal of Digital Curation, 3(2), 112-120. https://doi.org/10.2218/ijdc.v3i2.62

Kumar, A., Boehm, M., Yang, J., \& Columbus, B. (2017). Data Management in Machine Learning: Challenges, Techniques, and Systems Who We Are Motivation: A Data-Centric View of ML. https://adalabucsd.github.io/papers/Slides_2017_Tutorial_SIGMOD.pdf

Lieberman, M. (2014). Visualizing Big Data : Social Network Analysis By Michael Lieberman. Digital Research Conference.

Wang, J., Tang, Y., Nguyen, M., \& Altintas, I. (2015). A Scalable Data Science Workflow Approach for Big Data Bayesian Network Learning. Proceedings - 2014 International Symposium on Big Data Computing, BDC 2014, 16-25. https://doi.org/10.1109/BDC.2014.10

Wu, X., Zhu, X., Wu, G.-Q., \& Ding, W. (2014). Data Mining with Big Data Xindong. leeexplore.leee.Org, 1-26. https://ieeexplore.ieee.org/abstract/document/6547630/ 